\title{
Artroskopik remplisaj tekniği ve klinik sonuçları
}

\author{
Arthroscopic remplissage technique and clinical outcomes
}

\author{
Durmuş Ali Öçgüder, Enes Uluyardımcı, Umut Öktem
}

Ankara Yıldırım Beyazıt Üniversitesi, Ankara Şehir Hastanesi, Ortopedi ve Travmatoloji Kliniği, Ankara

\begin{abstract}
Hill-Sachs lezyonu (HSL) glenoidin ön kenarı tarafından oluşturulan humerus başının kompresyon kırığıdır. Tekrarlayan çıkıklardan sonra daha sık olmak üzere anterior omuz instabilitesi varlığında sıklıkla karşımıza çıkmaktadır. Hill-Sachs lezyonunun tedavisi anterior omuz instabilitesi sonrası nüks bakımından oldukça önemlidir. Tedavi seçenekleri sadece artroskopik Bankart onarımı (ABO), ABO'ya ek remplisaj prosedürü ve Latarjet prosedürü olarak sıralanabilir. Hangi tedavi yönteminin seçilmesi gerektiği, cerrahi sonrası klinik ve fonksiyonel sonuçlar ve nüks oranları için birincil belirleyici faktördür. Bu nedenle "glenoid iz", "angaje olan" veya "angaje olmayan HSL" ve "iz üzerinde/iz dışı lezyon" kavramlarını anlamak bir tedavi stratejisi belirlemek için önemlidir. Uygun cerrahi endikasyon varlığında ABO'ya ek olarak uygulanan remplisaj tekniğiyle tatmin edici klinik sonuçlar alınabilmektedir. Ayrıca remplisaj sonrası ortaya çıkması beklenebilecek hareket kısıtlılığı da ihmal edilebilir seviyelerdedir. Remplisaj ve $A B O$ kombine tedavisi tek başına $A B O$ 'ya kıyasla daha düşük instabilite nüks oranları sağlar ve Latarjet prosedürüne kıyasla daha az morbidite ve daha az komplikasyonla benzer nüks oranlarına sahiptir.
\end{abstract}

Anahtar sözcükler: artroskopik Bankart onarımı; Hill-Sachs; instabilite; omuz çıkığı; remplisaj
Hill-Sachs lesion is a compression fracture caused by anterior edge of the glenoid. It is frequently encountered in the presence of anterior shoulder instability, especially with the presence of recurrent dislocations. Treatment of Hill-Sachs lesion is very important in terms of recurrence after anterior shoulder instability. Treatment options can be listed as only arthroscopic Bankart repair (ABR), additionally remplissage procedure to $A B R$, and Latarjet procedure. Which treatment modality should be chosen is the primary determining factor for clinical and functional outcomes and recurrence rates after surgery. Therefore, understanding the concepts of "glenoid track", "engaged" or "non-engaged HSL" and "on-track/offtrack lesion" is important for determining a treatment strategy. In the presence of appropriate surgical indications, satisfactory clinical results can be obtained with the combination of remplissage technique and arthroscopic Bankart repair. In addition, the limitation of movement that can be expected to occur after remplissage procedure is also at negligible levels. Combined treatment of remplissage and Arthroscopic Bankart repair provides lower instability recurrence rates compared to $\mathrm{ABR}$ alone and has similar recurrence rates with less morbidity and fewer complications than the Latarjet procedure.

Key words: arthroscopic Bankart repair; Hill-Sachs; instability; shoulder dislocation; remplissage

kapsülü orta hareket aralığında gevşektir, bu da humerus başının glenoid soket üzerinde herhangi bir yönde serbestçe hareket etmesine izin verir. Humerus başının bu translasyonuna "laksisite" denir. Ön ve arka çekmece testleri (yükleme ve kaydırma testi) ve sulkus testi, kol orta hareket aralığındayken yapılır çünkü bu testler omuz eklemindeki gevşekliği tespit etmeye yöneliktir.

Omuz stabilitesi, kolun pozisyonuna ve omuz çevresindeki kasların aktivitesine bağlıdır. Kapsüloligamentöz yapılar, kol son hareket aralığındayken ana stabilizatörlerdir, oysa negatif eklem içi basınç ve kongergindir, bu da humerus başının glenoid soket üzerinde yer değiştirmesini engeller. ${ }^{[2]}$ Öte yandan, omuz 
kavite-kompresyon etkisi, kolun orta hareket aralığında ana stabilizatörleridir. Negatif eklem içi basınç ${ }^{[3,4]}$ ve konkavite-kompresyon etkisiyle ${ }^{[5]}$ orta aralıkta stabilite sağlanır. Kol gevşemiş hâldeyken omuz, kolun ağırlığıyla aşağı doğru çekilir ve bu durum humerus başını glenoid sokete emen ve humerus başının aşağı doğru çevrilmesini önleyen negatif bir eklem içi basınç yaratır. Kol aşağı çekilirse (sulkus testi), humerus başında değişen derecelerde aşağı doğru translasyon olabilir. Genel olarak, eklem içi basıncın negatif değeri, aşağı doğru çekmenin artmasıyla lineer olarak artar. ${ }^{[4]}$ Negatif değerdeki bu artış, humerus başının negatif basınç ve ağırlığı arttığında daha fazla translasyonunu engeller. Eklem içi basıncın dış yüke tepkisi, eklem hacminin yanı sıra eklem kapsülü ve kaslar gibi çevreleyen yumuşak doku zarfının kalınlığı ve kalitesi ile belirlenir. ${ }^{[6]}$ Eklem içi basıncın tepki vermesindeki değişen dereceler nedeniyle, omuz gevşekliği için normal bir değer yoktur. Bazı insanlarda, büyük miktarda gevşeklik nedeniyle orta hareket aralığında omuzda subluksasyon hatta çıkık meydana gelebilir. Bu subluksasyon veya çıkık hiçbir semptoma eşlik etmiyorsa, bu gevşeklik sadece fizyolojiktir ve herhangi bir tedaviye gerek yoktur.

Kol abdüksiyondayken kas kasılması meydana gelir gelmez, omuz kaslarının kasılma kuvveti humerus başını glenoid sokete doğru çeker ve bu da humerus başının translasyonuna karşı bir direnç kuvveti oluşturur. Bu dengeleyici mekanizmaya "konkavite kompresyon etkisi"denir. ${ }^{[5]}$ Bu etki, glenoid içbükeyliğinin derinliğine ve kas tarafından oluşturulan kasılma kuvvetinin büyüklügüne bağlıdır.

Glenoid yuva, üst-alt yönde, ön-arka (AP) yöne göre iki kat daha derindir. ${ }^{[7]}$ Sonuç olarak humerus başına sabit bir kompresif kuvvet altında translasyon yapabilmek için gereken kuvvet üst-alt yönde ön-arka yöne göre iki kat daha fazladır. Translasyon kuvveti/basınç kuvveti oranı, kararlılık oranı olarak tanımlanır ve bu oran AP yönde 0,33 ila 0,35 ve üst-alt yönde 0,59 ila $0,64{ }^{\prime}$ tür. ${ }^{[8]}$

Omuz kasları tarafından ortaya çıkan kuvvetin büyüklüğü ve yönü, kolun aktivitesine ve pozisyonuna bağlıdır. Büyüklügü ve yönü ne olursa olsun, glenoid sokete karşı bileşke kuvvetin dik bileşeniyle stabilite oranı çarpılarak direnç kuvveti belirlenir. Son hareket aralığında, omuz eklemi kapsülünün bir kısmı gerginleşir ve kolun daha fazla hareket etmesini engeller. Örneğin; inferior glenohumeral ligamenti (iGHL) içeren antero-inferior kapsül, kol abdüksiyon, dış rotasyon ve yatay ekstansiyondayken gerginleşir. Sıkı kapsülo-ligamentöz yapı, sıkı kapsül yönünde humerus başının stabilizatörü olarak işlev görür. Inferior glenohumeral ligamentin direncinden daha büyük bir kuvvet uygulanırsa IGHL yırtılabilir ve humerus başı glenoid soketten dışarı çıkabilir. Bu pato- lojik olan ve tedavi edilmesi gereken travmatik bir omuz çıkığıdır. Bu nedenle, çıkığın kolun hangi pozisyonunda meydana geldiğine ve semptomların eşlik edip etmediğine bağlı olarak bir çıkık fizyolojik veya patolojik olabilir.

\section{GLENOID KEMIK DEFEKTi}

Önceleri glenoidin üçte biri veya daha büyük bir kemik kusurunun tedavi edilmesi gerektiği söylenmiştir. ${ }^{[9,10]}$ Ancak bu üçte birlik değerlendirme çok özneldir ve nicel değildir. Çünkü glenoidin üçte birinin tam olarak ne kadar olduğunu belirlemek mümkün değildir. Üçte bir veya dörtte bir gibi öznel bir değerlendirme kullanıldığı sürece, tedavi edilmesi gereken bir kusurun kritik boyutu belirlenemez. Bu düşünceden yola çıkılarak yapılan bir çalışmada dört farklı boyutta (glenoid uzunluğunun $\% 9$ 'u, \%21'i, \%34'ü ve \%46'sı) antero-inferior glenoid kemik defektleri oluşturularak Bankart onarımından sonra her bir kemik defekti boyutunda omuz stabilitesi ölçülmüştür. ${ }^{[1]}$ Omuz son hareket aralığında, yani abdüksiyon ve dış rotasyonda olduğu sürece, glenoidin en büyük kemik kusurunda bile omuz stabilitesinin korunduğu görülmüştür. Bunun nedeni bu pozisyonda, onarılan antero-inferior kapsülün gergin hale gelmesi ve büyük bir glenoid defekt varlığında bile humerus başının anterior translasyonunu engellemesidir. Bununla birlikte, kol orta hareket aralığına geldiğinde, sıkı kapsül tarafından daha fazla koruma olmadığından ve glenoid soket humerus başını tutmak için çok sığ olduğundan, humerus başı belirli bir boyutta glenoid kusuru ile kolayca antero-inferior olarak glenoidden çıkmıştır. Bu kusur boyutu, glenoid uzunluğunun \%21'i veya glenoid genişliğinin $\% 28$ 'i kadar bulunmuştur. Bu bulgular bize açık bir șekilde glenoid kemik defektinin son aralık instabilitesiyle değil, orta aralık instabilitesiyle ilgili olduğunu söylemektedir. Yapılan bir biyomekanik çalışmada da glenoidin ön kenarında oluşturulan bir glenoid defektiyle ilk olarak, stabiliteye etki edebilecek herhangi bir yumuşak doku katkısı olmadan stabilite oranını kullanıp kemik stabilitesi ölçülerek, bir deplase etme kontrol çalışması yapılmış ve Bankart onarımından sonra omuz stabilitesi ölçülmüştür. ${ }^{[12]} \mathrm{Bu}$ çalışmalar, glenoid defektinin kritik boyutunun glenoid genişliğinin \%25’i olduğunu göstermiştir. ${ }^{[12,13]}$

\section{Glenoid Kusurun Değerlendirilmesi}

Direkt radyografi, bilgisayarlı tomografi (BT), üç boyutlu $B T$, manyetik rezonans görüntüleme (MRG) ve artroskopi gibi glenoidin kemik kusurunu değerlendirmenin çeşitli yöntemleri vardır. Üç boyutlu BT kullanılarak glenoidin karşıdan yani yüzeyinden görünümü, glenoid kemik defektinin en doğru değerlendirmesini sağladığı için günümüzde referans olarak kabul edilmektedir. ${ }^{[14-20]}$ 
Glenoidin karşıdan görünümünde, iki şeye karar vermemiz gerekir: birincisi orijinal glenoid şeklini nasıl tahmin edeceğimiz ve ikincisi kusur boyutunu nasıl ifade edeceğimiz.

Illki için iki yöntem vardır: En uygun daireyi kullanmak $^{[18,21,22]}$ ve kontralateral glenoidi referans olarak kullanmak. ${ }^{[17,23]}$ Bilgisayarlı tomografi taramalarında bilateral omuz görüntüleri taramaya dahil edildiğinde iki omuz arasındaki uzunluk ve genişlik farkı <\%1 olduğunda, karşı taraf omuzda instabilite yoksa kontralateral glenoidi kullanmak en iyi yöntem gibi görünmektedir. ${ }^{[24]}$

Kusur boyutunu ifade etmek için ise iki yöntem vardır: Alan ölçümü ve doğrusal ölçüm. Çoğu insan doğrusal ölçümü kullanmayı tercih eder çünkü kolaydır ve özel bir yazılıma gerek yoktur, sadece bir cetvel yeterlidir (Şekil $1)$.

\section{HILL-SACHS LEZYONU (HSL)}

Hill-Sachs lezyonu (HSL) glenoidin ön kenarı tarafından oluşturulan, humerus başının kompresyon kırığıdır. Hill-Sachs lezyonu, anterior instabilite varlığında sıklıkla görülür. Hill-Sachs lezyonu prevalansı ilk çıkıktan sonra \%65 ila \%67 ve tekrarlayan çıkıktan sonra \%84 ila \%93 olarak bildirilmiştir. ${ }^{[25,26]}$

Genellikle, küçük bir HSL tüberkulum majusun yakınında bulunurken, büyük bir HSL, tüberkulum majustan uzağa, daha medial olarak uzanır. Küçük ve dar ancak medial yerleşimli bir HSL, optimum tedavi seçeneğinin seçilmesinde özel dikkat gerektirir. ${ }^{[27]}$

Hill-Sachs lezyonu, orta aralık stabilitesi ile ilgili değildir çünkü orta aralık harekette glenoidten uzakta bulunur. Kol, abdüksiyon ve dış rotasyonda posterior son aralıktayken glenoid, HSL'nin bulunduğu humerus başının posterolateral kısmına gelir. Bu kol pozisyonunda HSL tamamen glenoid tarafından kapatılırsa herhangi bir instabiliteye neden olamaz. Ancak glenoid kapsamının dışındaysa glenoidin ön kenarıyla birleşerek çıkığa neden olabilir. Bu nedenle glenoid kemik kusurundan farklı olarak HSL, son aralıktaki instabilite ile ilişkilidir.

\section{Hill-Sachs Lezyonuna Bağlı İnstabilite Riskinin Değerlendirilmesi}

Belirtildiği gibi HSL, son aralık instabilitesi ile ilgilidir. $\mathrm{Bu}$, angajman (HSL'nin glenoid kenara oturması) ve çıkık riskinin, HSL'nin glenoide göre göreceli boyutuna ve konumuna bağlı olduğu anlamına gelir. Hill-Sachs lezyonu riskini değerlendirmek için iki yöntem vardır.

Birinci yöntem dinamik muayenedir. Artroskopik cerrahi sırasında HSL ve glenoid arasındaki rölatif ilişki değerlendirilebilir. Önemli olan bu dinamik muayenenin Bankart tamiri sonrası yapılmasıdır (Şekil 2,3). Bankart onarımından önce HSL'nin glenoid ile etkileşime girip girmediği önemli değildir; bilmek istediğimiz daha sonra angajman riski olup olmadığıdır. Dinamik muayeneyi gerçekleştirmenin amacı budur ve bu nedenle Bankart ona-

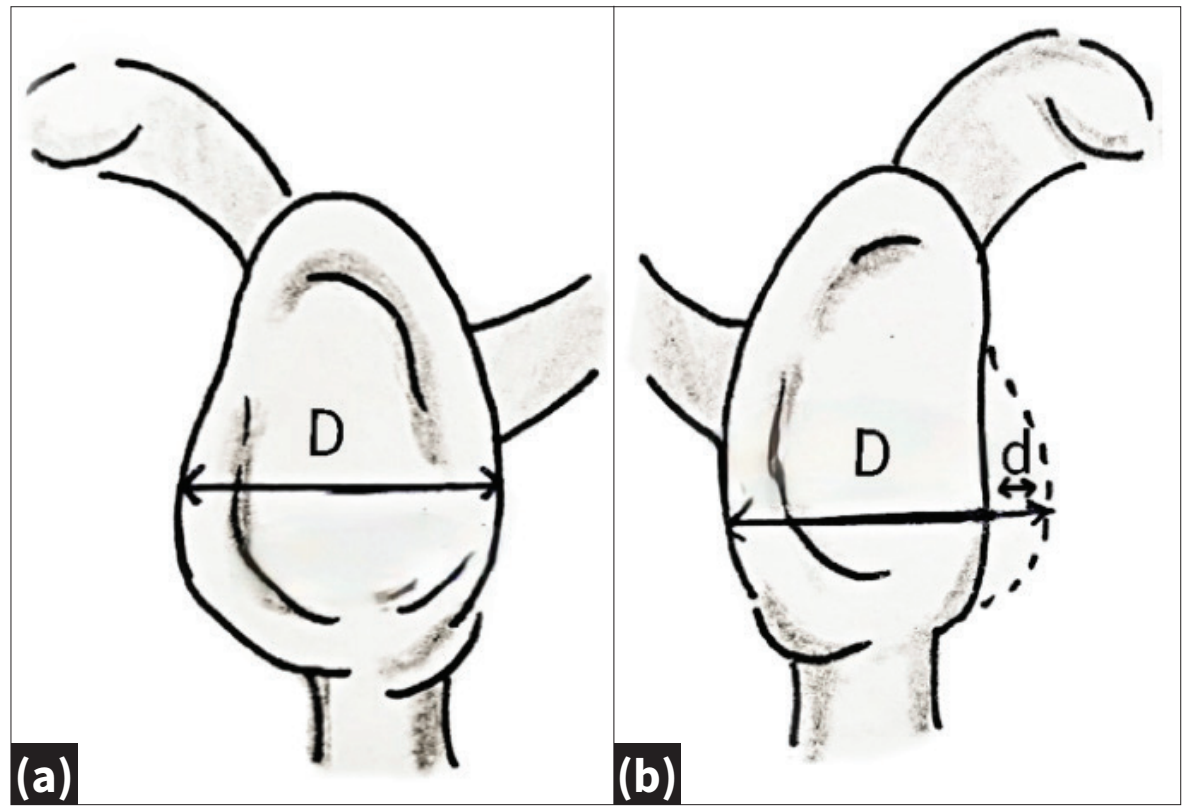

Şekil 1.a-b. Direkt ölçüm: Sağlam olan kontralateral glenoidte 'D' sağlam glenoidin genişliğini temsil eder (a), glenoid kemik defekti olan ilgili tarafta ' $D$ ' sağlam taraftan gelir ve sağlam glenoid genişliği ‘D’ ile eksik glenoidin genişliği arasındaki fark, kusur genişliği ‘d'dir (b). 


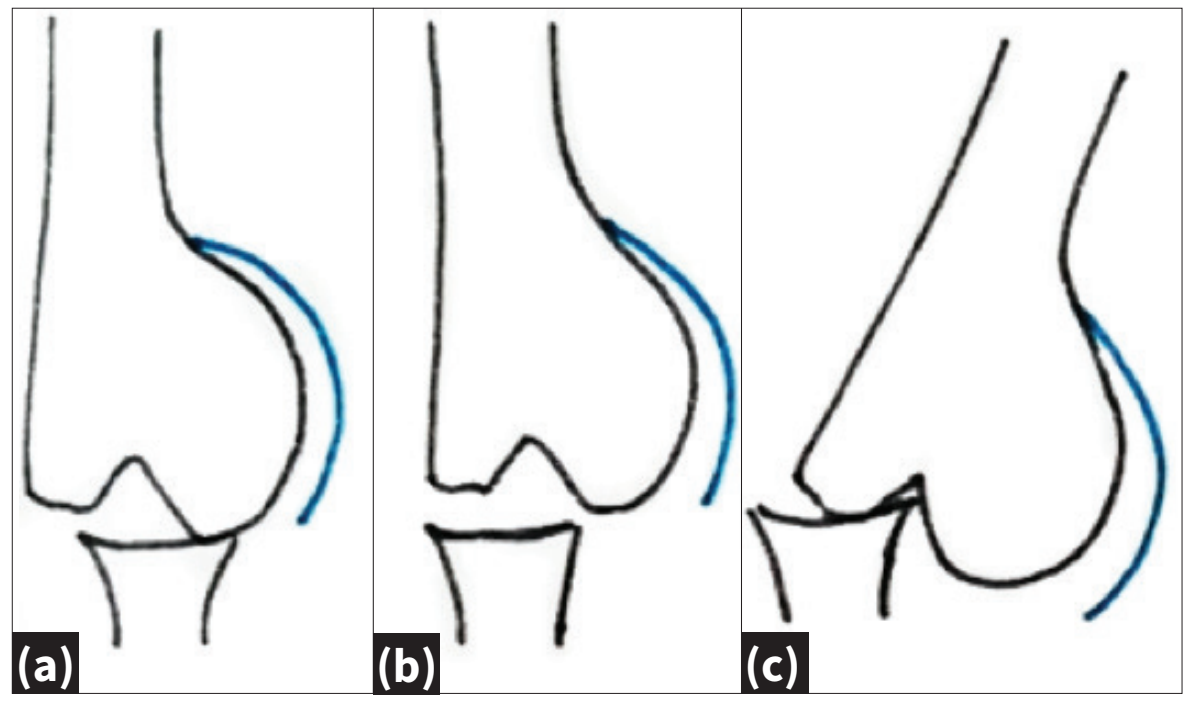

Şekil 2.a-c. Bankart onarımı öncesi dinamik muayene: Bankart lezyonundan dolayı omuz anteriora doğru instabil (a), dinamik muayene boyunca humerus başının anteriora translasyonu (b), sonuç olarak Hill-Sachs lezyonu glenoide oturur ve baş disloke olur (c).

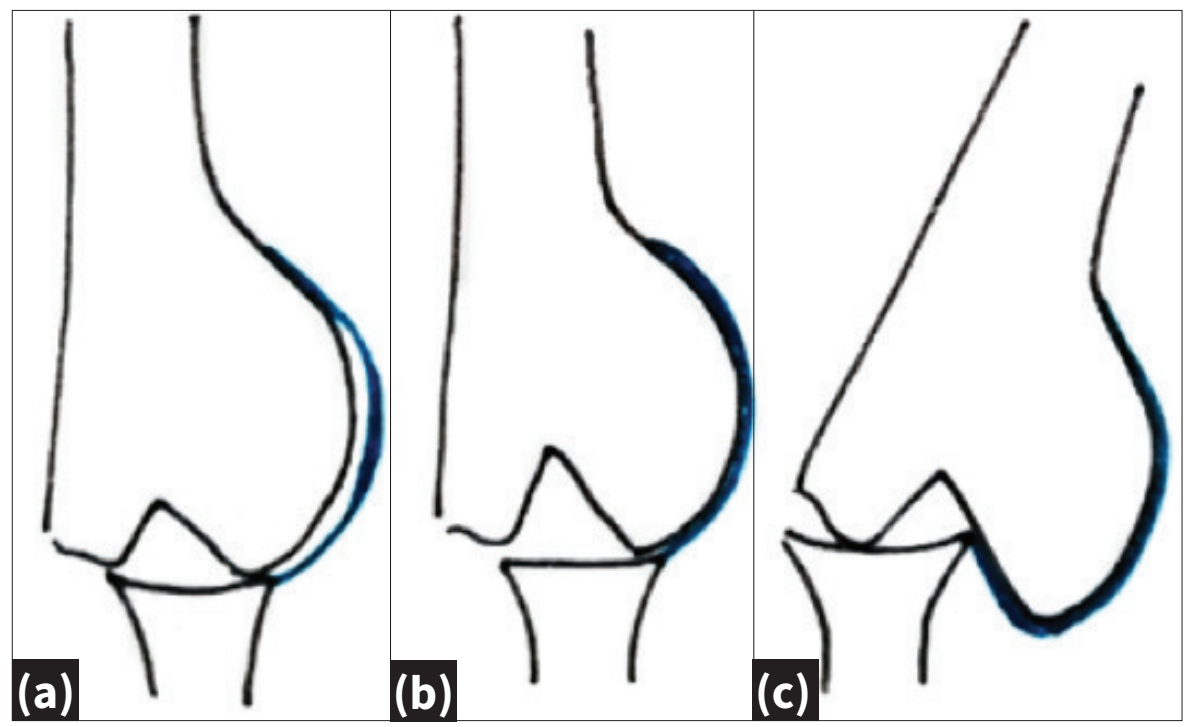

Şekil 3.a-c. Bankart onarımı sonrası dinamik muayene: Hill-Sachs lezyonu (a), Bankart onarımı sonrası sıkı anterior kapsül sayesinde omuz glenoide oturmuyor (b), Bankart onarımı sonrası humerus başı glenoide yine de oturuyorsa buna "angaje Hill-Sachs lezyonu" denir (c).

rımından sonra yapılmalıdır. Ne yazık ki çoğu araştırmacı dinamik incelemeyi Bankart onarımından önce gerçekleştirir ve bu inceleme olumluysa bunu angaje HSL olarak tanımlarlar. ${ }^{[28,29]}$ Bu raporlara göre, HSL ile angaje olma prevalansı \%34 ila \%52 idi. ${ }^{[28,29]}$ Bunun angaje HSL belirlemenin doğru yolu olmadığını ve prevalansı olduğundan fazla tahmin ettiğini düşünen Parke ve ark. Bankart onarımından önce ve sonra angajmanı değerlendirdiler. Dokuz yüz seksen üç omuz stabilizasyonu serisinde 70 omuz, Bankart onarımından sonra dinamik muayene sırasında bir angajman gösterdi ve bu vakalara remplisaj eklediler. Bu verilerle angaje HSL prevalansını \%7 (983'de 70) buldular. ${ }^{[30]}$ Dinamik muayene yönteminin dezavantajı, dinamik muayene sırasında Bankart onarımın zarar görme riskinin olmasıdır.

İkinci yöntem, glenoid track (glenoid iz) kavramını kullanmaktır. Hill-Sachs lezyonunun glenoidin ön kenarına angaje olma riski kol posterior son hareket aralığındayken en yüksektir çünkü bu pozisyonda glenoid HSL ile üst üste biner. Yapılan çalışmalarda glenoide göre HSL riskini değerlendirmek amacıyla, glenoid iz konsepti tanımlandı. ${ }^{[31,32]}$ Glenoid iz kol posterior son hareket aralığında 


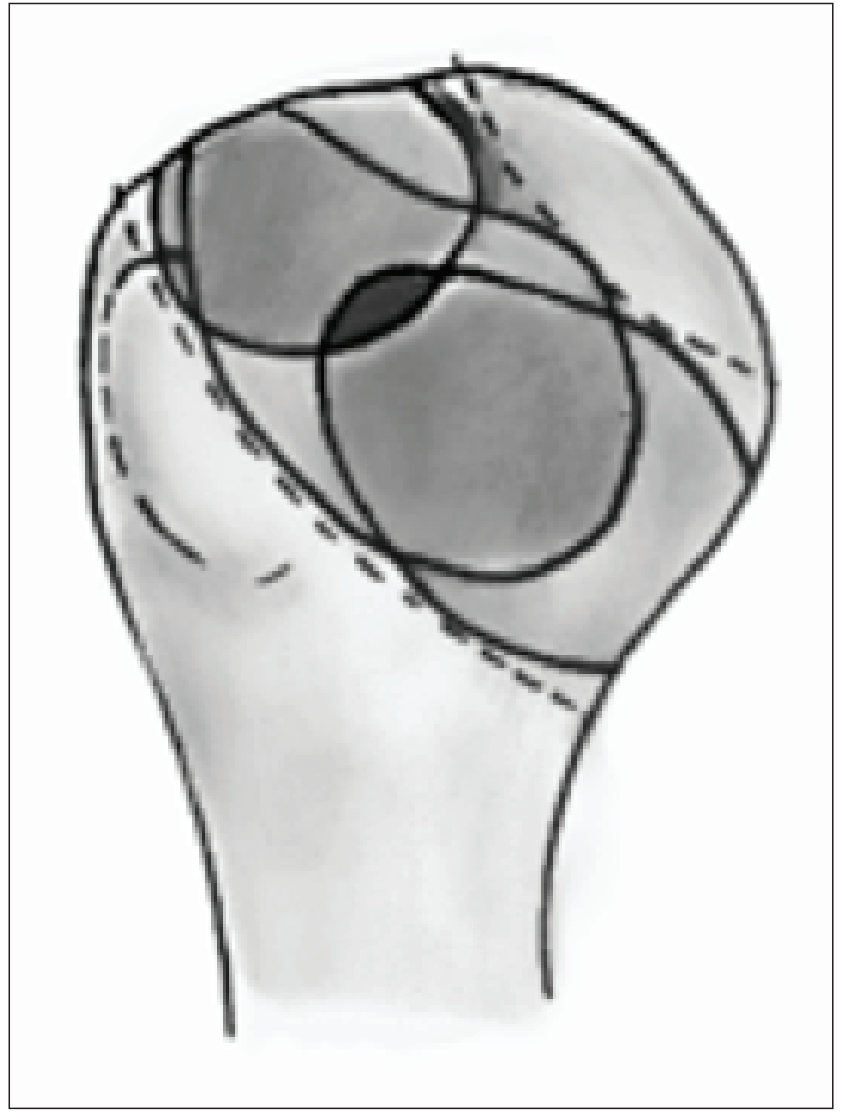

Şekil 4. Glenoid iz: Omuz posterior son hareket aralığında maksimum eksternal rotasyon ve maksimum horizontal ekstansiyonda hareket ederken, glenoid humerus başının posterior eklem yüzeyinde hareket eder. Bu temas yüzeyine "glenoid iz" denir. olduğunda posterior humeral artiküler yüzeyin glenoid ile temas ettiği alandır (Şekil 4). Hill-Sachs lezyonu glenoid iz içinde kalırsa, herhangi bir angajman/çıkık meydana gelmez. Ancak glenoid izden çıkarsa, HSL glenodin ön kenarına angaje olabilir ve yeni bir çıkığa neden olabilir.

Glenoid izin medial marjı ile rotator manşetin ayak izinin medial marjı arasındaki mesafe olarak tanımlanan glenoid iz genişliği; kadavralarda glenoid ön-arka genişliğinin $\% 84^{\prime}$ ü $^{[33]}$, canlılarda kol $90^{\circ}$ abdüksiyondayken glenoid ön-arka genişliğinin \%83'ü olarak bulunmuştur. ${ }^{[32]}$

Günlük pratiğimizde üç boyutlu BT ile hem glenoid yüzeyini hem de humerusun ilgili arka yüzeyini değerlendiriyoruz. İlk olarak, sağlam glenoidin genişliği ölçülür ve glenoid ön-arka genişliğinin \%83'ü hesaplanır $(0,83$ D) (Şekil 5a). Ardından, bu \%83 değeri $(0,83$ D) ilgili glenoidin direkt karşıdan görünümüne uygulanır (Şekil $5 b)$. Glenoidte kemik kusuru varsa, glenoid izinin gerçek genişliğini $(0,83 \mathrm{D}-\mathrm{d})$ elde etmek için kusur genişliği d'nin $\% 83$ değerinden (0,83 D) çıkarılması gerekir. Bu genişlik (0,83 D-d) humerus başının arka görünümüne uygulanır. Hill-Sachs lezyonunun medial kenarı glenoid iz içinde kalırsa, bu HSL'nin glenoidin ön kenarına angaje olma riski yoktur ve buna "angaje olmayan HSL" denir. HillSachs lezyonu, glenoid izin medial kenarı üzerinde daha medial olarak uzanırsa HSL'nin glenoidin ön kenarına angaje olma riski vardır ve buna "angaje HSL" denir. ${ }^{[23,34]}$

Bununla birlikte, yukarıda açıklanan bu terimler neredeyse her zaman yanlış kullanıı ve çok fazla kafa karışıklığına neden olur. Bu karışıklığı önlemek için Di Giacomo

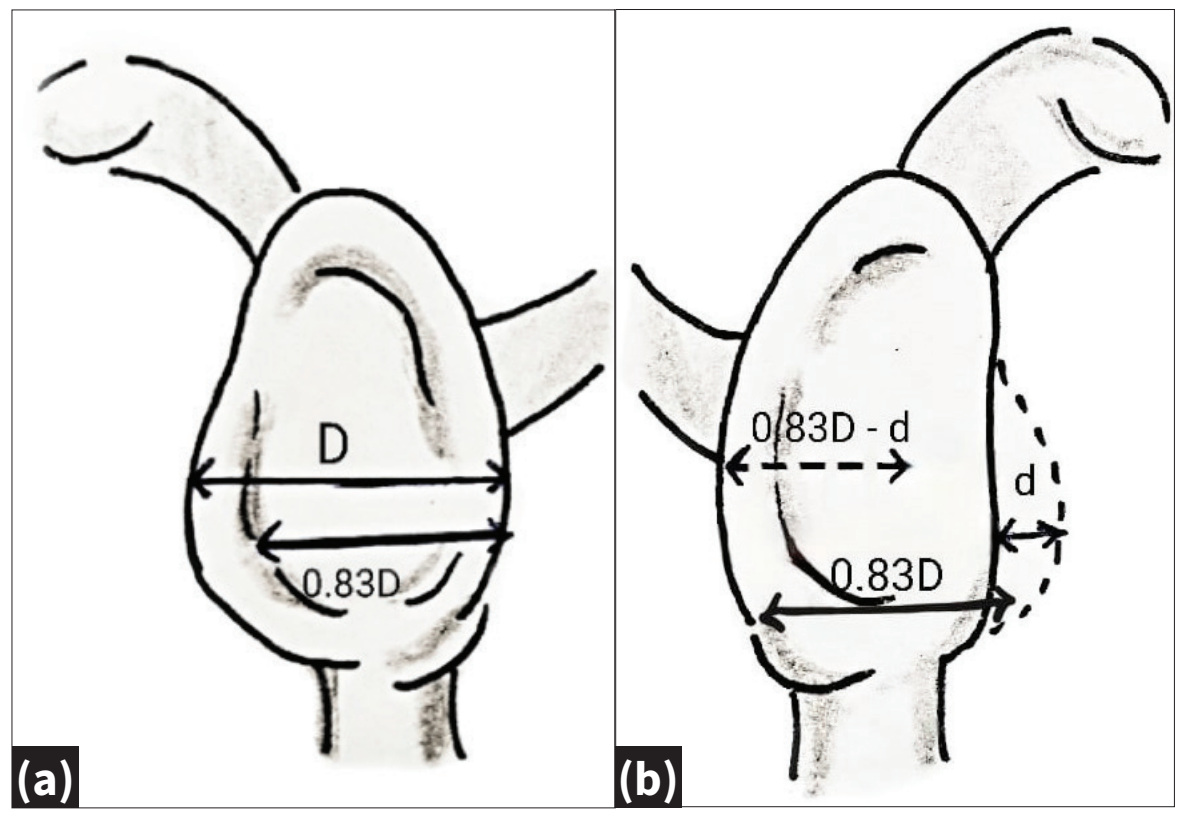

Şekil 5.a-b. Sağlam glenoidin 'karşıdan' görünümünde, glenoid genişliğinin \%83'ü elde edilir (0.83D) (a). ilgili taraftaki glenoid kusuru "d" olarak belirtilmiştir. Glenoid iz: şekilde kesikli çift başlıklı okla gösterilen 0.83D-d değeridir (b). 
ve ark. yaptıkları bir çalışmada yeni bir terminoloji; "iz üzerinde HSL" ve "iz dışı HSL" (on track ve off track) kavramlarını önerdiler. ${ }^{[23]}$ Hill-Sachs lezyonu, glenoid iz üzerinde kalırsa (iz üzerinde lezyon), angajman riski yoktur. Hill-Sachs lezyonu glenoid izin dışındaysa (iz dışı lezyon), angajman ve çıkık riski vardır.

Son zamanlarda, bu iz üzerinde (on track)/iz dışı (off track) kavramının geçerliliğini gösteren bazı klinik çalışmalar bulunmaktadır. Locher ve ark. artroskopik Bankart onarımı yapılan 100 hastayı geriye dönük olarak analiz ettiler. Bu 100 hastadan 88'inde iz üzerinde ve 12'sinde iz dışı HSL mevcuttu. İz üzerinde HSL olan hastaların \%6'sında (88 hastanın beşi); iz dışı HSL'si olan hastaların ise \%33'ünde (12 hastadan dördü) nüks gelişmişti. [35] Shaha ve ark. artroskopik Bankart onarımı yapılan 57 hastayı incelediler. İz üzerinde HSL olan hastalarda nüks oranı \%8; iz dışı HSL olan hastalarda ise \%75'ti. İz dışı HSL olan hastaların, iz üzerinde HSL olan hastalara kıyasla nüks yaşama olasılık oranı (odds ratio) 8,3 idiNüksü öngörmek için iz dışı kavramın pozitif prediktif değeri $\% 75$ iken, >\%20 olan glenoid kemik kaybının pozitif prediktif değeri \%43'tü. İz dışı yönteminin doğru olduğu ve artroskopik anterior stabilizasyon için değerlendirilen tüm hastaların rutin ameliyat öncesi değerlendirmesinde uygulanması gerektiği sonucuna vardılar. ${ }^{[36]}$

Yukarıda bahsedilen glenoid iz, angaje olan ve angaje olmayan HSL, iz üzerinde ve iz dışı lezyon kavramlarını anlamak bir tedavi stratejisi belirlemek için önemlidir.

\section{TEDAVI STRATEJISi}

İz üzerinde/iz dışı konseptine dayalı olarak tedavi stratejisi aşağıdaki gibidir: ${ }^{[23]}$

- İz üzerinde HSL ve glenoid kemik kaybı $<\% 25$ olan omuzlar için sadece $\mathrm{ABO}$ yeterlidir.

- İz üzerinde HSL ve glenoid kemik kaybı $\geq \% 25$ olan omuzlarda Latarjet prosedürü gibi kemik fiksasyon ameliyatları gerekir.

- İz dışı HSL ve <\%25 glenoid kemik kaybı ile, remplisaj iyi bir prosedür olabilir. Bununla birlikte, hasta tam bir dış rotasyon gerektiren bir fırlatma sporcusuysa veya hasta yüksek tekrarlama riski olan bir temas/çarpışma sporcusuysa, o zaman Latarjet prosedürü daha iyi bir yöntemdir çünkü iz dışı bir lezyonu, iz üzerinde bir lezyona çevirir ve omuza ek stabilite sağlar. ${ }^{[33]}$ Ragbi oyuncularında Latarjet prosedürünün sonucu oldukça tatmin edicidir. ${ }^{[37]}$

- İz dışı HSL ve glenoid defekti $\geq \% 25$ olanlarda kemik fiksasyon intiyacı mevcuttur. Latarjet prosedürü, iz dışı bir lezyonu, iz üzerinde bir lezyona dönüştürebilir. Bununla birlikte Latarjet prosedüründen sonra HSL hâlâ iz dışı ise Latarjet prosedürüne remplisaj veya kemik grefti eklenmesi gerekir.

\section{CERRAHI TEKNIK}

Bipolar kemik kaybının (hem HSL hem glenoid kemik hasarı) eşlik ettiği anterior glenohumeral instabilitesi olan hastaların tedavisi zordur. Tedavinin amacı humerus başının glenoid kubbe içinde kalmasını sağlayarak stabiliteyi yeniden oluşturmaktır. $\mathrm{Bu}, \mathrm{ABO}$ ve remplisaj kombinasyonu (glenoid kemik kaybı $<\% 25$ ) veya Latarjet prosedürü (glenoid kemik kaybı $\geq \% 25$ ) olarak iki şekilde sağlanabilmektedir. Biz bu derlemede remplisaj ve $A B O$ cerrahi tedavisinden bahsedeceğiz.

\section{Ameliyat Öncesi Hazırlık}

Rejyonel ve genel anestezinin ardından, hasta ameliyat masasına şezlong pozisyonunda yatırılarak cerrahi yapılacak olan üst ekstremite steril olarak boyanır ve örtülür. Sonrasında ilk olarak anestezi altında muayene yapılır. Anestezi altıda muayene 3. derece anterior translasyonun doğrulanmasını ve HSL'nin angajmanını içermelidir.

\section{Portal Açılması, Glenohumeral Eklem İnspeksiyonu ve Karar Verme}

Illk olarak standart artroskopik posterior gözlem portali açılır ve $30^{\circ}$ artroskop ile tanısal artroskopi yapılır. Ardından, anterosuperior işlem portali rotator interval arasından açılarak düşük-profil $5 \mathrm{~mm} \times 7 \mathrm{~cm}$ kanül, enstrümantasyonu kolaylaştırmak için yerleştirilir. Glenohumeral debridman için, 3,75 mm radyofrekans koter cihazı ve artroskopik shaver kullanılır. Takiben antero-superior labrum, olası glenolabral artiküler defekt lezyonu ve HSL debride edilir (Şekil 6). Her iki kemik defekti dikkatlice anteriordan ve posteriordan görüntülenmelidir. Anterior glenoidte kemik parçası mevcutsa kemik kalitesi değerlendirilmelidir. Artroskopik Bankart onarımı, kemik parçası iyi kalitede ve yeterli boyuttaysa uygun bir seçenek gibi görünmektedir.

\section{Artroskopik Remplisaj Hazırlığı}

Artroskop ilk olarak görüntüleme ve remplisaj hazırlığı için anteriora yerleştirilir. Hill-Sachs lezyonunun debridmanını takiben, Hill-Sachs defektine infraspinatus tenodezinin (remplisaj) iyileşmesini artırmak için mikrokırık uygulanır. Ardından artroskop subakromial aralığa ayrı olarak yerleştirilir ve remplisaj prosedürünü iyi görüntüleme için total bursektomiyi içeren artrosko- 


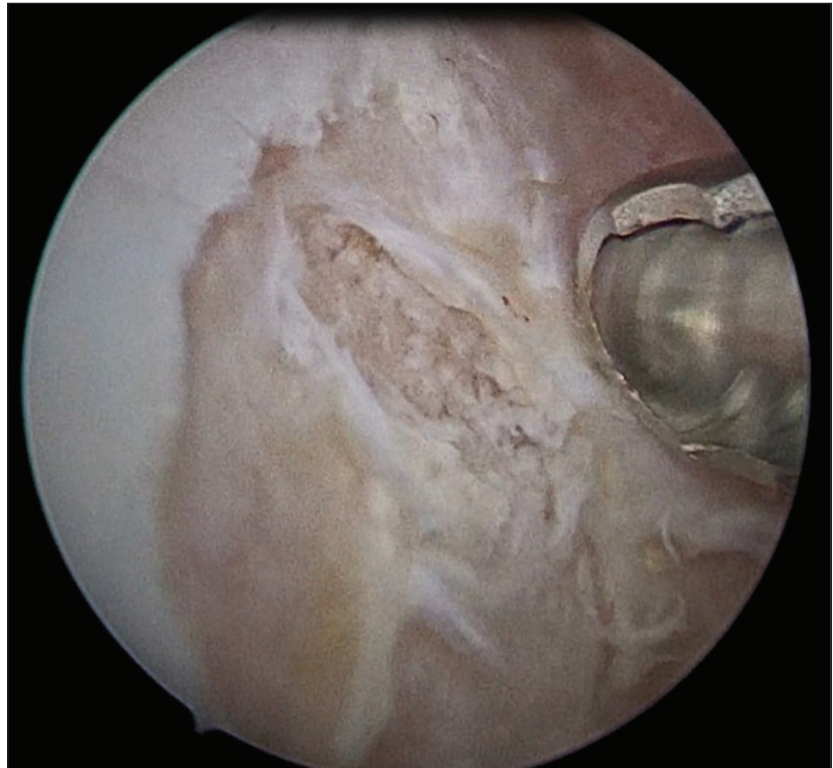

Şekil 6. Hill-Sachs lezyonunun shaver yardımıyla debride edilmesi.

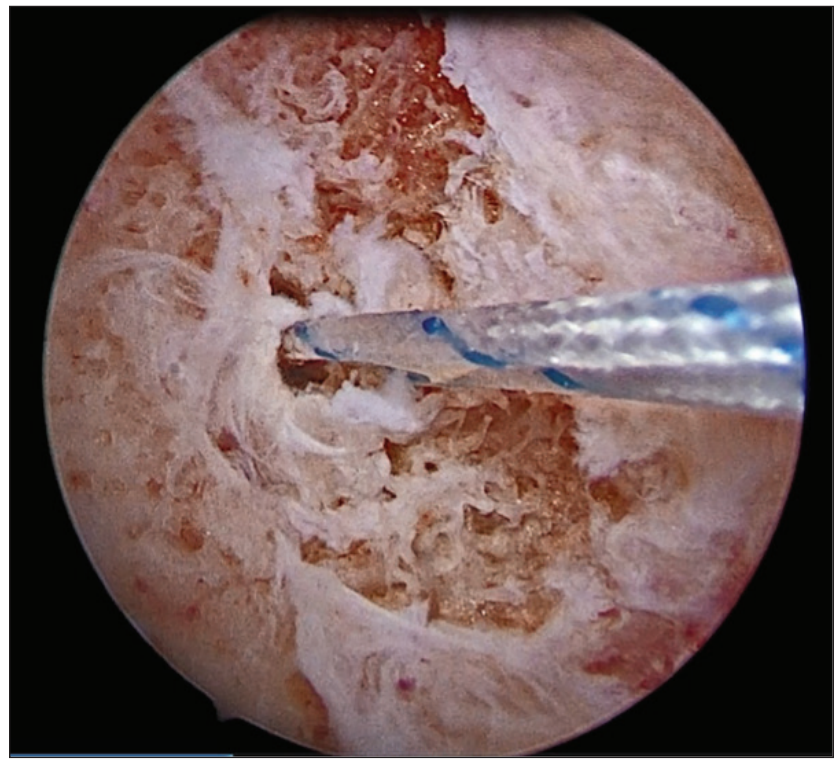

Şekil 7. Ankorun Hill-Sachs defektinin artiküler yüzüne yerleştirilmesi.

pik subakromial dekompresyon yapılır. Posterior portal sütür geçirmek ve düğüm atmak için açılır. Takiben, artroskop anterior portale tekrar yerleştirilerek, bir adet 2,8 $\mathrm{mm}$ soft ankor Hill-Sachs defektinin artiküler yüzeyine yerleştirilir (Şekil 7). Sütürler matris konfigürasyonunda infraspinatus içinden subakromial aralığa geçirilir ve aksesuar postero-lateral portalden dışarı alınır (Şekil 8). Artroskopik Bankart onarımın hareket açıklığını azaltabileceği göz önünde bulundurarak sütürlere bu noktada düğüm atılmamalıdır.

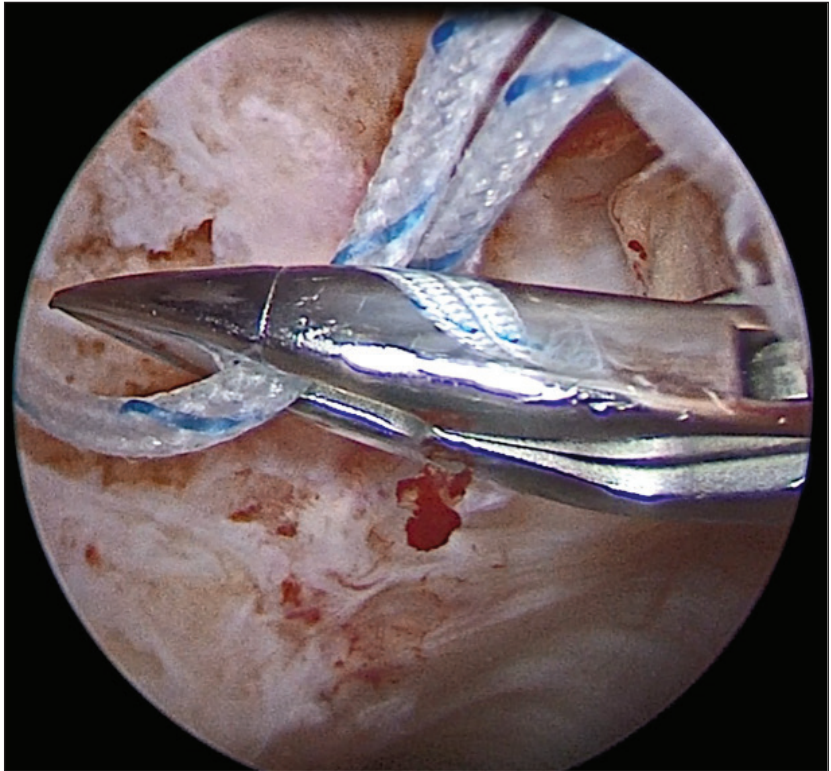

Şekil 8. Sütürler bird pick yardımıyla infraspinatus içinden subakromial aralığa alınır ve aksesuar postero-lateral portalden dışarı alınır.

$\mathrm{Bu}$ işlemlerden sonra inferior glenolabral ayrışma için labrum raspa yardımıyla iyice sıyrılır ve ankorun uygulanacağı yere raspa yardımıyla kanlandırma işlemi uygulanır. İki adet $1,8 \mathrm{~mm}$ soft ankor uygulanarak sütür geçiricilerle labrumdan ipler geçirilir ve matris şeklinde onarılır.

\section{Artroskopik Remplisaj Prosedürünün Tamamlanması}

Artroskop anterosuperior portal kullanılarak subakromial aralığa tekrar yerleştirilir. Remplisaj prosedürü, kayan ve kilitlenen iki adet matris dikişinin sabitlenmesiyle tamamlanır ve kalan sütür materyali kesilir. Artroskop daha sonra remplisajı görüntülemek için rotator aralıktan ekleme yerleştirilir. Remplisaj, Hill-Sachs defektini etkili bir şekilde eklem dışı yapar. Dinamik muayene sırasında, Hill-Sachs lezyonu glenoidin anterior kenarına angaje olmamalıdır. Takiben omuz bolca lavaj ve drene edilerek, tüm artroskopik aletler çıkarılıp, portaller kapatılır.

\section{Cerrahi Sonrası Bakım}

Cerrahi sonrası omuza antero-posterior grafi çekilmelidir. Ameliyat edilen kol, ameliyat sonrası erken pasif hareket açıklığı sağlanacak şekilde bir askıya alınır. Dış rotasyon ilk dört hafta boyunca $30^{\circ}$ ye kısıtlanır. Beşinci haftadan itibaren tam pasif hareket açıklığı uygulanır ve ardından sırasıyla aktif-asistif ve aktif hareket açıklığı başlanarak askı kullanımı sonlandırılır. 


\section{KLINIK SONUÇLAR VE TARTIŞMA}

Bipolar kemik kaybının eşlik ettiği anterior glenohumeral instabilitesi (AGI) olan hastaların tedavisi zordur. Tedavinin amacı humerus başının glenoid kubbe içinde kalmasını sağlayarak stabiliteyi yeniden oluşturmaktır. Anterior glenohumeral instabilitesi olan hastalarda ileri bipolar kemik kaybı (BKK) hem glenoid hem de humerus başındaki kemik defektlerinin boyutuna ve konumuna bağı ılarak bireysel tedavi stratejileri gerektirir. ${ }^{[38,39]}$ Bipolar kemik kaybı olduğu bu gibi durumlarda, humerus başının iz üzerinde mi yoksa iz dışında mı olduğunu belirlemek önemli bir faktördür. ${ }^{[40,41]} \mathrm{Bu}$ tahminde, kombine kemik kaybı ve yeri hesaba katılır. Ek olarak, anterior glenoid kemik kaybının miktarı AGI'de BKK tedavisinin seçiminde temel belirleyicidir.

İz dışı humerus lezyonları mevcut olduğunda, remplisaj ve Latarjet prosedürleri, tek başına Bankart onarımından daha üstün kabul edilir, çünkü bu prosedürler, Hill-Sachs lezyonunun anterior glenoid kenarla birleşmesini azaltır. Remplisaj, infraspinatus ve postero-inferior kapsülü kullanarak defekti doldurmak için uygulanır. Sonuç olarak, Hill-Sachs lezyonunun angajmanı önlenir ve lezyon özellikle dış rotasyon ve abduksiyonda iz üzerinde kalır ve bu durum yalnızca Bankart onarımıyla elde edilemez. Yakın zamanda yapılan bir biyomekanik sistematik inceleme bu bulguları doğruladı ve literatürdeki çalışmaların çoğunda remplisajın, Hill-Sachs lezyonunun anterior glenoide angajmanını sürekli olarak önlediğini bildirdi. ${ }^{[42]}$ Bu biyomekanik veriler ABO ile kombine edilen remplisajın tek başına $A B O$ uygulanan prosedürlere göre beş kat daha düşük bir nüks oranına sahip olduğunu gösteriyor.

Yapılan bir meta-analiz çalışmasında tek başına ABO yapılan 123 hasta ve remplisaj da eklenen 114 hastayı içeren dört çalışma rapor edilmiştir. Ortalama Rowe skoru, $A B O$ prosedüründen sonra 84,2 iken, remplisajdan sonra 91,3 olarak bulunmuştur. Ek remplisaj prosedürü lehine istatistiksel olarak anlamlı bir fark bulunmuştur. Yine aynı meta-analiz çalışmasında toplam nüks (subluksasyon ve çıkık da dâhil) oranları değerlendirilmiş ve tek başına $170 \mathrm{ABO}$ prosedürünü ve remplisajın da uygulandığı 157 prosedürü içeren yedi çalışmanın sonuçlarına göre; $A B O$ uygulanan hastaların \%16,8'inde tekrarlayan instabilite meydana gelirken remplisaj da eklenen hastalarda bu oran \%3,2 olarak rapor edilmiştir. ${ }^{[43]}$ Tüm bunlardan yola çıkarak tek başına ABO ile karşılaştırıldığında, remplisaj prosedürü tekrarlayan instabilite oranlarını azaltma potansiyeline sahiptir.

Remplisajla ilgili temel endişe, remplisajın tenodez etkisine bağlı olarak cerrahi sonrası eklem hareket açıklığında azalmaya yol açabilmesi olmuştur. Hem glenoid hem de humerus başında belirgin BKK olan aradaki vakalarda, Bankart prosedürü ve remplisaj kombinasyonu kapsüler hacmi ciddi olarak azaltmakta olup glenohumeral eklem hareketlerini kısıtlayabilir. ${ }^{[44]}$ Toplam 207 hastayı içeren sekiz makalenin analiz edildiği bir sistematik derleme çalışmasında (tüm bu çalışmalar remplisajla birlikte $A B O$ uygulanan hastaları içeriyor) genel olarak addüksiyonda dış rotasyonda ortalama 5, $6^{\circ}(-40$ ila +30$)$, abdüksiyonda dış rotasyonda $11,3^{\circ}(-50$ ila +7$)$ ve iç rotasyonda $0,9^{\circ}$ (-4 ila 0 ) azalma bulunmuş ${ }^{[45]}$, öte yandan fleksiyonu değerlendiren dört çalışmadan üçünde remplisajı takiben fleksiyonda azalma tanımlanmıştır. ${ }^{[46-50]}$ Ancak yapılan bir meta-analiz çalışmasında eklem hareket açıklığında azalmayla ilgili endişeler giderilmiştir. ${ }^{[43]}$ Eşlik eden Hill-Sachs lezyonları olan hastalarda anterior omuz instabilitesi için $A B O$ ile birlikte remplisaj, tek başına $A B O$ ve açık Latarjet prosedürüyle karşılaştırılmıştır:

- $\quad A B O$ ile remplisaj yapılan hastalarda sadece $A B O$ yapılan hastalara göre istatistiksel olarak anlamlı daha yüksek Rowe skoru ve daha düşük tekrarlayan çıkık oranları bulunmuştur. Fakat nüks nedeniyle revizyon, spora dönüş ve öne fleksiyonla abduksiyonda dış rotasyonu içeren eklem hareket aralığında istatiksel olarak anlamlı farklıık saptanmamıştır.

- Açık Latarjet prosedürü ve $A B O$ ile remplisaj uygulanan hastalar arasında total nüks oranları, Rowe skoru, tekrarlayan çıkık, nüks nedeniyle revizyon, öne fleksiyonla abduksiyonda dış rotasyonu içeren eklem hareket açıklığı, spora dönüş ve total revizyon oranlarından hiçbirinde istatistiksel olarak anlamlı fark bulunamamıştır.

Bu çalışmanın en önemli bulgusu, remplisajla birlikte $A B O$ 'nun tek başına $A B O$ 'ya kıyasla daha düşük nüks oranları sağlaması ve Latarjet prosedürüne kıyasla daha az morbidite ve daha az komplikasyonla birlikte benzer nüks oranları sağlamasıdır. Ek olarak remplisajın, tek başına ABO ile karşılaştırıldığında, öne fleksiyon veya dış rotasyonda hareket açıklığı değerlendirildiğinde ameliyat sonrası hareket açıklığını önemli ölçüde değiştirmediği bulunmuştur. Bulgular angaje bir HSL varlığında anterior omuz instabilitesi için ABO'ya ilave bir remplisajın uygulanmasını desteklemektedir.

Mook ve ark., sadece Latarjet prosedürü ile tedavi edilen ciddi BKK olan hastalarda, Hill-Sachs lezyonu tamir edilmemiş ise humerus başının iz dışı olabileceğini göstermişlerdir. ${ }^{[51]} \mathrm{Bu}$ vakalarda, remplisaj ve Latarjet kombinasyonu göz önüne alınmalıdır. ${ }^{[52]}$ Kavramsal olarak bu yaklaşım mantıklı olsa da her iki prosedürü birlikte gerçekleştirmek teknik açıdan zorlu olup literatürde iyi açıklanmamıştır. 


\section{SONUÇ}

Uygun cerrahi endikasyon ve tecrübeli bir cerrah tarafından yapılan artroskopik Bankart onarımı ve remplisaj tekniğiyle tatmin edici klinik sonuçlar alınabilmektedir ve remplisaj sonrası ortaya çıkması beklenebilecek hareket kısıtlılığ da ihmal edilebilir seviyelerdedir. Remplisaj ve ABO kombine tedavisi tek başına ABO'ya kıyasla daha düşük instabilite nüks oranları sağlar ve Latarjet prosedürüne kıyasla daha az morbidite ve daha az komplikasyonla benzer nüks oranlarına sahiptir. Remplisaj ve $A B O$ kombine tedavisi tek başına ABO ile karşılaştırıldığında, öne fleksiyon veya dış rotasyonda cerrahi sonrası hareket açıklığını önemli ölçüde değiştirmemektedir. Anterior omuz instabilitesine eşlik eden angaje bir Hill-Sachs lezyonu varlığında artroskopik Bankart onarımına ek olarak remplisaj prosedürü uygulanması gereklidir.

\section{KAYNAKLAR}

1. Hertz H. Significance of the limbus glenoidalis for the stability of the shoulder joint. Wien Klin Wochenschr Suppl 1984;152:123.

2. Itoi E, Morrey BF, An KN. Biomechanics of the shoulder. In: Matsen FA, Wirth MA, Lippitt SB, Rockwood CA, (eds). The Shoulder. 4th ed.: Saunders/Elsevier, Philadelphia 2009; p. 213-65. Crossref

3. Kumar VP, Balasubramaniam P. The role of atmospheric pressure in stabilising the shoulder. An experimental study. J Bone Joint Surg 1985;67-(5):719-21. Crossref

4. Itoi E, Motzkin NE, Browne AO, Hoffmeyer P, Morrey BF, An KN. Intraarticular pressure of the shoulder. Arthroscopy 1993;9:406-13. Crossref

5. Matsen FA III, Harryman DTII, Sidles JA. Mechanics of glenohumeral instability. Clin Sports Medicine 1991;10:783-88. Crossref

6. Itoi E. Pathophysiology and treatment of atraumatic instability of the shoulder. J Orthop Sci 2004;9:208-13. Crossref

7. Howell SM, Galinat BJ. The glenoid-labral socket. A constrained articular surface. Clin Orthop Relat Res 1989;243:122-5. Crossref

8. Lippitt SB, Vanderhooft JE, Harris SL, Sidles JA, Harryman DT II, Matsen FA III. Glenohumeral stability from concavity-compression: A quantitative analysis. J Shoulder Elbow Surg 1993;2:27-35. Crossref

9. Matsen FA III, Thomas SC. Glenohumeral instability. In: Evarts C, (ed). Surgery of the Musculoskeletal System. 2nd ed. Churchill Livingstone, New York 1990:1439-69.

10. Matsen FA III, Thomas SC, Rockwood CA Jr, Wirth MA. Glenohumeral instability. In: Rockwood CA Jr, Matsen FA III (eds). The Shoulder. Philadelphia: W. B. Saunders, 1998:611754.

11. Itoi E, Lee SB, Berglund LJ, Berge LL, An KN. The effect of a glenoid defect on antero-inferiorstability of the shoulder after Bankart repair: a cadaveric study. J Bone Joint Surg Am 2000;82-A:35-46. Crossref
12. Yamamoto N, Itoi E, Abe H, Kikuchi K, Seki N, Minagawa H, et al. Effect of an anterior glenoid defect on anterior shoulder stability: a cadaveric study. Am J Sports Med 2009;37:949-54. Crossref

13. Yamamoto N, Muraki T, Sperling JW, Steinmann SP, Cofield $\mathrm{RH}$, Itoi $\mathrm{E}$, et al. Stabilizing mechanism in bonegrafting of a large glenoid defect. J Bone Joint Surg Am 2010;92-A. Crossref

14. Rokous JR, Feagin JA, Abbott HG. Modified axillary roentgenogram. A useful adjunct in the diagnosis of recurrent instability of the shoulder. Clinical Orthop Relat Res 1972;82:84-6. Crossref

15. Garth WP Jr, Slappey CE, Ochs CW. Roentgenographic demonstration of instability of the shoulder: the apical oblique projection. A technical note. J Bone Joint Surg Am 1984;66-A:1450-3. Crossref

16. Baudi P, Righi P, Bolognesi D, et al. How to identify and calculate glenoid bone deficit. La Chirurgia degli organi di movimento 2005;90:145-52. (In Italian)

17. Griffith JF, Antonio GE, Tong CW, Ming CK. Anterior shoulder dislocation: quantification of glenoid bone loss with CT. AJR Am J Roentgenol 2003;180:1423-30. Crossref

18. Huijsmans PE, Haen PS, Kidd M, Dhert WJ, van der Hulst VPM, Willems WJ.Quantification of a glenoid defect with three-dimensional computed tomography and magnetic resonance imaging: a cadaveric study. J Shoulder Elbow Surg 2007;16:803-9. Crossref

19. Burkhart SS, Debeer JF, Tehrany AM, Parten PM. Quantifying glenoid bone loss arthroscopically in shoulder instability. Arthroscopy 2002;18: 488-91. Crossref

20. Provencher MT, Bhatia S, Ghodadra NS, et al. Recurrent shoulder instability: current concepts for evaluation and management of glenoid bone loss. J Bone Joint Surg Am 2010;92A:133-51. Crossref

21. Sugaya H, Moriishi J, Dohi M, Kon Y, Tsuchiya A. Glenoid rim morphology in recurrent anterior glenohumeral instability. J Bone Joint Surg Am 2003;85-A:878-84. Crossref

22. Huijsmans PE, de Witte PB, de Villiers RV, Wolterbeek WD, Warmerdam P, Kruger NR, et al. Recurrent anterior shoulder instability: accuracy of estimations of glenoid bone loss with computed tomography is insufficient for therapeutic decision-making. Skeletal Radiol 2011;40: 1329-34. Crossref

23. Di Giacomo G, Itoi E, Burkhart SS. Evolving concept of bipolar bone loss and the Hill-Sachs lesion: from "engaging/non-engaging" lesion to "on-track/off-track" lesion. Arthroscopy 2014;30:90-8. Crossref

24. Shi L, Griffith JF, Huang J, Wang D. Excellent side-to-side symmetry in glenoid size and shape. Skeletal Radiol 2013;42:17115. Crossref

25. Spatschil A, Landsiedl F, Anderl W, Imhoff A, Seiler H, Vassilev I, et al. Posttraumatic anterior-inferior instability of the shoulder: arthroscopic findings and clinical correlations. Arch Orthop Trauma Surg 2005;126(4):217-22. Crossref

26. Yiannakopoulos CK, Mataragas E, Antonogiannakis E. A comparison of the spectrum of intra-articular lesions in acute and chronic anterior shoulder instability. Arthroscopy 2007;23:98590. Crossref 
27. Kurokawa D, Yamamoto N, Nagamoto H, Omori Y, Tanaka M, Sano $\mathrm{H}$, et al. The prevalence of a large Hill-Sachs lesion that needs to be treated. J Shoulder Elbow Surg 2013;22(9):1285-9. Crossref

28. Cho SH, Cho NS, Rhee YG. Preoperative analysis of the HillSachs lesion in anterior shoulder instability: how to predict engagement of the lesion. Am J Sports Med 2011;39:2389-95. crossref

29. Zhu YM, Lu Y, Zhang J, Shen JW, Jiang CY. Arthroscopic Bankart repair combined with remplissage technique for the treatment of anterior shoulder instability with engaging Hill-Sachs lesion: a report of 49 cases with a minimum 2-year follow-up. Am J Sports Med 2011;39:1640-7. Crossref

30. Parke CS, Yoo JH, Cho NS, Rhee YG. Arthroscopic remplissage for humeral defect in anterior shoulder instability: Is it needed? [abstract] 39th Annual Meeting of Japan Shoulder Society, 2012.

31. Yamamoto N, Itoi E, Abe H, Minagawa H, Seki N, Shimada Y, et al. Contact between the glenoid and the humeral head in abduction, external rotation, and horizontal extension: a new concept of glenoid track. J Shoulder Elbow Surg 2007;16:64956. Crossref

32. Omori Y, Yamamoto N, Koishi H, Futai K, Goto A, Sugamoto K, et al. Measurement of the glenoid track in vivo as investigated by 3-dimensional motion analysis using open MRI. Am J Sports Med 2014;42: 1290-5. Crossref

33. Yamamoto N, Muraki T, An KN, Sperling JW, Cofield RH, Itoi $\mathrm{E}$, et al. The stabilizing mechanism of the Latarjet procedure: a cadaveric study. J Bone Joint Surg Am 2013;95:1390-7. Crossref

34. Itoi E, Yamamoto N. Shoulder instability: treating bone loss. Current Orthopaedic Practice 2012;23:609-15. Crossref

35. Locher J, Wilken F, Beitzel K, Buchmann S, Longo UG, Denaro $V$, et al. Hill-Sachs Off-track lesions as risk factor for recurrence of instability after arthroscopic Bankart repair. Arthroscopy 2016;32:1993-9. Crossref

36. Shaha JS, Cook JB, Rowles DJ, Bottoni CR, Shaha SH, Tokish JM. Clinical validation of the glenoid track concept in anterior glenohumeral instability. J Bone Joint Surg Am 2016;98:191823. Crossref

37. Neyton L, Young A, Dawidziak B, Visona E, Hager JP, Fournier Y, et al. Surgical treatment of anterior instability in rugby union players: clinical and radiographic results of the Latarjet-Patte procedure with minimum 5-year follow-up. J Shoulder Elbow Surg 2012;21:1721-7. Crossref

38. Longo UG, Loppini M, Rizzello G, Romeo G, Huijsmans PE, Denaro V. Glenoid and humeral head bone loss in traumatic anterior glenohumeral instability: A systematic review. Knee Surg Sports Traumatol Arthrosc 2014;22:392-414. Crossref

39. Di Giacomo G, De Vita A, Costantini A, de Gasperis N, Scarso P. Management of humeral head deficiencies and glenoid track. Curr Rev Musculoskelet Med 2014;7:6-11. Crossref

40. Yamamoto N, Itoi E, Abe H, Minagawa H, Seki N, Shimada Y, et al. Contact between the glenoid and the humeral head in abduction, external rotation, and horizontal extension: A new concept of glenoid track. J Shoulder Elbow Surg 2007;16:64956. Crossref
41. Locher J, Wilken F, Beitzel K, Buchmann S, Longo UG, Denaro $V$, et al. Hill-Sachs offtrack lesions as risk factor for recurrence of instability after arthroscopic Bankart repair. Arthroscopy 2016;32:1993-9. Crossref

42. Lazarides AL, Duchman KR, Ledbetter L, Riboh JC, Garrigues GE. Arthroscopic remplissage for anterior shoulder instability: a systematic review of clinical and biomechanical studies. Arthroscopy 2019;35:617-28. Crossref

43. Hurley ET, Toale JP, Davey MS, Colasanti CA, Pauzenberger L, Strauss EJ, et al. Remplissage for anterior shoulder instability with Hill-Sachs lesions: a systematic review and meta-analysis. J Shoulder Elbow Surg 2020;(12):2487-94. Crossref

44. Burkhart SS, De Beer JF. Traumatic glenohumeral bone defects and their relationship to failure of arthroscopic Bankart repairs: significance of the inverted-pear glenoid and the humeral engaging Hill-Sachs lesion. Arthroscopy 2000;16:67794. Crossref

45. Rashid MS, Crichton J, Butt U, Akimau PI, Charalambous CP. Arthroscopic "Remplissage" for shoulder instability: a systematic review Knee Surg Sports Traumatol Arthrosc 2016;24:578-84. Crossref

46. Yiannakopoulos CK, Mataragas E, Antonogiannakis E. A comparison of the spectrum of intra-articular lesions in acute and chronic anterior shoulder instability. Arthroscopy 2007;23:98590. Crossref

47. Owens BD, Nelson BJ, Duffey ML, Mountcastle SB, Taylor DC, Cameron $\mathrm{KL}$, et al. Pathoanatomy of first-time, traumatic, anterior glenohumeral subluxation events. J Bone Joint Surg Am 2010;92:1605-11. Crossref

48. Latarjet M. Treatment of recurrent dislocation of the shoulder. Lyon Chir 1954;49:994-7.

49. Provencher MT, Ghodadra N, LeClere L, Solomon DJ, Romeo AA. Anatomic osteochondral glenoid reconstruction for recurrent glenohumeral instability with glenoid deficiency using a distal tibia allograft. Arthroscopy 2009;25:446-52. Crossref

50. Shin SJ, Koh YW, Bui C, Jeong WK, Akeda M, Cho NS, et al. What is the critical value of glenoid bone loss at which soft tissue Bankart repair does not restore glenohumeral translation, restricts range of motion, and leads to abnormal humeral head position? Am J Sport Med 2016;44:2784-91. Crossref

51. Mook W, Petri M, Greenspoon JA, Horan MP, Dornan GJ, Millett PJ. An evaluation of the clinical and anatomical predictors of outcomes at a minimum of 2 years following the Latarjet procedure for recurrent anterior shoulder instability with glenoid bone loss. Am J Sports Med 2016;44:1407-16. Crossref

52. Ranne JO, Sarimo JJ, Heinonen OJ, Orava SY. A combination of Latarjet and remplissage for treatment of severe glenohumeral instability and bone loss. A case report. J Orthop 2013;10:46-8. Crossref 